\title{
Measuring consumer emotions during live sports broadcasts
}

\author{
Robert S. Smith ${ }^{\mathrm{a}}$ \& Yukyoum Kim ${ }^{\mathrm{b}^{*}}$ \\ ${ }^{a}$ Assistant Professor, Department of Marketing, Suffolk University, Boston, USA \\ ${ }^{b}$ Professor, Department of Physical Education, Seoul National University, Seoul, Korea
}

\begin{abstract}
Though the role of emotion has been largely acknowledged across most consumer settings, only recently has this interest transferred to the various contexts in which sports are consumed. The purpose of the present research is to highlight the role of emotions during the viewing of televised sports programming. Across two studies, the manifestation of emotional arousal is empirically established. Additionally, the emotional valence (i.e., the extent to which a stimulus is perceived as affectively positive, neutral, or negative) of marketing stimuli are assessed. A methodology for measuring baseline levels of emotional valence for commercial advertising is outlined. Study 1 is presented in which empirical support is established for the fleeting influence that live sports consumption has upon emotional arousal. This is followed by a review of Study 2, which establishes a methodology for measuring the emotional valence perceived by consumers for embedded commercial advertising. Finally, the practical and research implications of these findings are discussed.
\end{abstract}

Key words: fan emotions, arousal, valence, sports broadcast, sport advertisement

\section{Measuring consumer emotions during live sports broadcasts}

The sport industry represents a popular context for marketers to communicate information regarding their product. However, the efficacy of delivering this message within a spectator sport setting is questionable. The enhanced arousal of sport fans and the unpredictable nature of this form of consumption represent unique parameters under which consumers are exposed to marketing stimuli. Currently, it is not known whether these conditions bolster or inhibit the utility of spectator sports as a medium for delivery.

Submitted : 14 October 2021

Revised : 7 December 2021

Accepted : 24 December 2021

Correspondence : ykim22@snu.ac.kr
Furthermore, inferences deriving from previous literature support contradictory predictions in this regard. First, researchers have argued that heightened levels of consumer involvement, arousal, and pleasure enhance the likelihood that the marketer's message is received by the consumer (Hsieh et al., 2014); whereas inadequate levels may lead to a diminished probability of attending to the information or sufficiently encoding it into memory (Trampe et al., 2010).

On the other hand, it is plausible that the emotional nature of spectator sports consumption negatively impacts memory for marketing information; memory researchers have issued multiple models that depict emotional processing as detrimental to human memory and other cognitive functions (Baddeley, 2013). Consumer psychologists have long argued for the 
important role of emotions in silently driving consumer decision making. Consumer behavior studies have shown their role in influencing food choices (Steptoe et al., 1995), the consumer experience in brick and mortar stores (Sherman et al., 1997), responses to salespeople (Babin et al., 1995), and the processing of advertising stimuli (Holbrook \& Batra, 1987). Taken together, various streams of consumer research across a variety of contexts have documented the substantial influence that affect and emotion have upon important cognitive and behavioral outcomes.

Though the role of emotion has been largely acknowledged across most consumer settings, only recently has this interest transferred to the various contexts in which sports are consumed. Prior focus has been placed on enduring affect, such as fan attachment, loyalty, identity, and relationship quality (Hill \& Green, 2012; Kim \& Trail, 2011). Although studies on emotions has been observed in a participant sport setting (Kang et al., 2011), examinations of the influence of relatively high-intensity, fleeting emotions upon live sports consumption are rare.

Although much of the knowledge derived from the general consumer behavior literature can be applied to the sports industry, this context is particularly intriguing due to the unique conditions under which fans consume sport. Relative to general consumption, fans engage with sport products in an exceedingly zealous manner. Many psychological variables, such as identification, commitment, emotional involvement, emotional attachment, attitudinal loyalty, and allegiance (Bee \& Havitz, 2010), have been used to represent the distinct way fans engage with sport products. Sport fans are considered to exhibit relatively high levels of each of these traits, which can be more generally referred to as consumers' attachment to the product. This view of sport consumption is well documented and makes up a robust domain of research within the sport management literature (Wann et al., 2001).

The aforementioned attachment processes represent the lasting psychological effects that are unique to the sport industry. However, this context can also be differentiated by the mechanisms at play during consumption. In general, the spectator sport industry facilitates a hedonic, social, and ritualistic form of consumption (Gantz et al., 2006), in which fans seek a dramatic and vicarious experience (Trail \& James, 2001). The dramatic nature of sport consumption stems from its unpredictable and dynamic characteristics, and it is amplified by a consumer's investment in its outcome (Wann et al., 2001). An emotional reaction is so desired by sport consumers that an event's failure to induce drama is often viewed as a negative or disappointing experience (Rainey et al., 2011). In fact, fans often explore methods of enhancing the dramatic nature of an event by manufacturing a personal stake in its outcome (e.g., gambling; Wulfert et al., 2005).

The purpose of the present research is to highlight the role of emotions during the viewing of televised sports programming. Across two studies, the manifestation of emotional arousal is empirically established. Additionally, the emotional valence (i.e., the extent to which a stimulus is perceived as affectively positive, neutral, or negative) of marketing stimuli are assessed.

\section{Literature Review}

Emotion is a "relatively brief episode of coordinated brain, autonomic, and behavioral changes that facilitate a response to an external or internal event of significance for the organism" (Davidson et al., 2003, p. 13). However, due to the pervading colloquial usage of emotion in everyday conversation, the term is often used interchangeably with several related concepts, including affect, feelings, and mood. Affect represents a general class of psychological phenomena which encompasses the remaining of the aforementioned concepts. Feelings can be described as the subjective manifestation of emotions (i.e., how emotions are experientially represented by the individual). Mood, on the other hand, refers to a "diffuse affective state that 
is often of lower intensity than emotion, but considerably longer in duration" (Davidson et al., 2003, p. 13).

\section{Emotional Arousal}

In the conceptual framework, emotional arousal and valence are examined separately. Arousal is associated with increased levels of noradrenaline, dopamine, and serotonin release (Lövheim, 2011). Each of these neurotransmitters is considered to enhance cognitive activity. Overall, the promotional influence of arousal upon memory has been well established. Across a variety of arousal-induction methods, including caffeine (Cotton, 2006), exercise (Coles \& Tomporowski, 2008), and fear (McNally, 1999), a large body of evidence has supported a positive arousal-memory relationship. The cognitive resource allocation model (CRAM; Kahneman, 1973) refers to a theoretical perspective that cognition is facilitated by a finite amount of resources, which are taxed by excessive biological, cognitive, and affective activity. Empirical research has supported the notion that emotions drain cognitive resources, thereby reducing the probability that a particular stimulus is encoded (Conway \& Engle, 1994).

An alternative explanation for the potentially negative influence of consumer arousal upon memory for marketing stimuli involves the selective attention mechanism An excessive amount of environmental stimuli render humans in a perpetual state of cognitive overload (Kirsh, 2000). Evolutionary psychologists have argued that primates have developed a cognitive system that implicitly selects stimuli considered to be salient or important and actively suppresses irrelevant information (Dukas, 2009). Emotional arousal is considered to lead to a narrowing of this theoretical selective attention funnel. A robust stream of literature has demonstrated that involvement in a traumatic event leads to enhanced memory for the causal stimulus and diminished memory for irrelevant stimuli (Mitchell et al, 2011). This phenomenon, known as peripheral neglect, implies that emotional activity during sport consumption would enhance memory for relevant information (e.g., game-related) and diminish memory for irrelevant information (e.g., marketing-related

Perhaps the most complex prediction pertains to the influence of psychological context incongruity upon subsequent retrieval processes. The aforementioned predictions (i.e., arousal enhancement, CRAM, and peripheral neglect) primarily pertain to encoding processes. However, according to the IPT literature, it is "not possible to understand memory by considering either encoding or retrieval in isolation; remembering reflects the interaction between encoding and retrieval processes" (Brown \& Craik, 2000, p. 99). IPT researchers now pose that the retrieval of information is largely driven by the occurrence of transfer appropriate processing (TAP; Morris et al., 1977). TAP refers to the extent to which conditions during retrieval facilitate the successful activation of target information within LTM. Particularly, the encoding specificity principle (Tulving \& Thomson, 1973) refers to the phenomenon that the retrieval of previously encoded information is partially dependent upon the extent to which the overall context during encoding simulates that of retrieval.

Based on the encoding specificity principle, the retrieval of marketing stimuli can be described as state dependent. That is, retrieval processes may be inhibited for consumers that encode marketing stimuli during non-neutral emotional states due to an inequality of internal conditions across encoding and retrieval stages. The state dependence of memory has been replicated across several contexts. For example, internal state dependency effects have been demonstrated across happy versus sad conditions (Bower et al.,1978) as well as depressed versus neutral conditions (Weingartner et al., 1977). Similarly, external state dependency has been demonstrated by altering the environmental context across encoding and retrieval. Godden and Baddeley (1975) famously demonstrated these effects using a sample of scuba divers. Participants learned (encoded) 
information while under water and subsequent memory was superior if tested while similarly under water.

The most common theoretical basis for these effects has been associative network theory (Bower, 1981; Clark \& Isen, 1982). This approach poses that the context during encoding is represented as a node in LTM. Activation of this node serves as a cue for retrieval. Therefore, the target memory trace (e.g., the sponsor of an event) is considered to be cognitively associated with the internal state (e.g., arousal, elation, anger) and environmental state (e.g., at the stadium, with friends, watching television) present during encoding. Failure to activate these contextual cues may decrease the likelihood that the target trace is triggered. Further, it is possible that this information is actually suppressed, as the memory search procedure may involve filtering out contextually incongruent traces in LTM (Bjork, 1989; Hartman \& Hasher, 1991). Associative network theory is derivative of the aforementioned IPT, as it pertains to the manner in which information is represented in, and retrieved from, LTM. These theories are implemented in conjunction to guide the present research.

\section{Emotional Valence}

Three theoretical predictions are evident within the emotions literature. The first involves what is known as the positive valence effect, which refers to the finding that a positively valenced emotional state enhances memory functioning (Ashby et al., 2002). Although PVE has received empirical support within the consumer behavior literature, some research has demonstrated that the PVE is eliminated when one's level of arousal is controlled (Choi et al., 2016; Mattes \& Cantor, 1982). These findings imply that valence state does not influence memory but rather arousal. It is an intuitive notion that a positive consumption experience inducing positive emotions would likely elicit higher levels of arousal.

In addition to examining one's valence state, researchers have studied the affective tone, or valence, of environmental stimuli and its relationship with memory processes. Overwhelmingly, researchers have demonstrated that probability of recall/recognition (POR/R) is significantly higher for valenced information (either positive or negative) as compared to neutrally toned stimuli (Eastwood et al., 2001; Vuilleumier \& Schwartz, 2001). However, the extent to which there is an advantage for positively versus negatively toned information is less clear. This study included a comparison of $\mathrm{POR} / \mathrm{R}$ for variously toned marketing stimuli.

Finally, similar to the aforementioned state dependency of information retrieval (see Figure 3), researchers have demonstrated that encoding processes may be state dependent, as well (Bower, 1981; Bower et al., 1981). That is, one's particular emotional valence state dictates the type of information that he/she attends to. A negatively emotional state is accompanied by an increased probability of selectively encoding negatively toned information from the environment (and vice versa). This theoretical prediction, known as state dependent encoding (SDE), was examined by testing the interaction of emotional valence state of sport consumers (i.e., positive, negative, and neutral) with the affective tone of marketing stimuli (i.e., positive, negative, and neutral).

Most studies of consumer affect have focused upon moods (e.g., Bagozzi et al., 1999; Myers \& Sar, 2015). This is likely due to the fact that emotions are comparatively difficult to invoke in laboratory settings, and inferring causal relationships is equally problematic in natural environments. Moods, on the other hand, are relatively easy to induce and occur much more frequently within general consumption contexts (Broach et al., 1995). Nevertheless, there are several established methods of measuring emotions in the affective sciences literature.

The first approach to measuring emotions is referred to as diagnostic assessment. A diagnostic measure of emotion refers to cases in which emotion is 
operationalized according to the observable bodily reactions of the participant (Matson \& Montrenes, 2020). Many researchers prefer diagnostic measures due to the theorized physical embodiment of emotions; some argue that emotions are defined by the behaviors that they enact (Zajonc, 1980). The simplest of these diagnostic measures involves third-party observation techniques. Some examples of these approaches include the Specific Affect Coding System (SPAFF; Gottman \& Krokoff, 1989), the Facial Action Coding System (FACS; Ekman \& Friesen, 1978), and the use of electromyographical (EMG) data, which examines muscles related to brow and lip movements (Cacioppo et al., 1988). However, there are several disadvantages to diagnostic measures of emotion, including involuntary facial contractions, the presence of unpredictable psycho-somatic reactions unrelated to emotion (e.g., attention to novel stimuli, breathing changes, etc.), the inability to distinguish between emotions, and the failure to address emotional valence (i.e., most diagnostic measures of emotion focus on emotional arousal; Matson \& Montrenes, 2020).

Another approach to the study of emotion involves self-report data. Self-report measures provide several advantages, including decreased researcher inference, speedy data collection, and cost effectiveness. Due to these characteristics, the measurement of emotions via questionnaires has become quite popular (Kang et al., 2011). Some popular examples of self-report emotion scales using a checklist procedure include the Mood Adjective Checklist (MACL, Nowlis, 1965) and the Mood Affect Adjective Checklist (MAACL; Zuckerman \& Lubin, 1965). Over time, however, researchers have begun to stray from the checklist format. The majority of modern conceptualizations represent variations of the arousal-valence view of emotion (Kapucu et al., 2021; Mehrabian \& Russell, 1974; Russell et al., 1989; Watson et al., 1988). Two popular examples include the Positive Affect Negative Affect Scale (PANAS; Watson et al., 1988), which represented emotional activity across two dimensions, namely Positive Affect (i.e., high levels of positively valenced arousal) and Negative Affect (i.e., high levels of negatively valenced arousal), and the Pleasure-Arousal-Dominance (PAD) scale (Mehrabian \& Russell, 1974).

One drawback to many self-report measures of emotion involve the length of the scale. Emotion is very temporally sensitive; the time necessary to complete the questionnaire may arguably restore the participant back to a baseline emotional state. The temporal issue inherent to the study of emotions has encouraged the adoption of smaller scales through the use of "emotional grids." For example, Russell and colleagues (1989) introduced the Affect Grid. Based on the two-dimensional view of emotion, the Affect Grid is a 9X9 matrix that requires only a single response from participants. Each participant rates his/her current emotional state by selecting the square that most adequately reflects the individual's level of emotional arousal and valence. The grid is divided into four quadrants, labeled excitement, relaxation, depression, and stress. Russell et al.'s (1989) approach facilitates repeated speedy and unobtrusive responses over an extended interaction with an emotional stimulus (e.g., a video).

Multidimensional accounts of emotion alleviate many of the measurement and internal validity concerns that are relevant to discrete conceptualizations. This view depicts emotion as the function of two dimensions, namely arousal and valence. Russell's model is very popular, and findings demonstrating the separability of the two dimensions regarding their differential impact upon cognition (particularly memory processes) enhances the relevance of this model to the current research (Kensinger, 2004). These studies portray that emotion and memory interact differently based on where the emotional stimulus is represented across a bi-dimensional space. Due to the present focus on the interaction of emotion and memory, this model is deemed to be particularly relevant to the current research. Further, the two-dimensional view has wide appeal due to its adaptability to more complex models. 
Multidimensional approaches offer several advantages, including the ability to quantify the emotion construct, the enhanced ease of interpretation (e.g., the arousal dimension is simpler to interpret than frustration), and the ability to adhere to and account for the common discrete emotions. Due to these advantages, most practical applications of emotions theory involve the implementation of a multidimensional measure. For instance, Mehrabian's (1996) Pleasure-Arousal-Dominance (PAD) model has been applied to research on consumer behavior, organizational behavior, and facial feature graphic design (Ashkanasy \& Cooper, 2008). Likewise, the proposed research will apply the circumplex model of emotions to enhance the current understanding of consumer responses to marketing stimuli within a spectator sport setting.

\section{Study 1}

The purpose of Study 1 is to empirically test the emotional volatility present during live sports consumption. The chosen context was mixed martial arts (MMA); specifically, two events from the ultimate fighting championship were utilized. The stimuli were originally selected through a subjective process based on viewer ratings and website publications with an aim toward obtaining two events with a polarizing emotional effect. The objective for this study was to empirically establish an arousal distinction between the High Arousal Recording (HAR) and the Neutral Arousal Recording (NAR). This context was selected for multiple reasons. First, MMA competitions are relatively brief ( $>30$ minutes) allowing the entirety of the contest to be presented, as opposed to the abridged recordings typical within the Sport Marketing literature (Bee \& Madrigal, 2012). Furthermore, match duration is easily equalized across conditions due to a typical lack of clock stoppages and commercial breaks. This is particularly important in memory research, as retention intervals have a large impact on POR
(Postman \& Phillips, 1965). Second, marketing stimuli are typically present throughout the competition. Depictions of such stimuli are presented in a later section of the manuscript. Third, MMA represents a spectator sport context considered to elicit particularly high levels of arousal and excitement (Lim et al., 2010). Finally, relative to more popular American sports (e.g., baseball, basketball, and football), it was predicted that fewer participants will know the outcome of the selected matches due to MMA's niche sport status (Mayeda \& Ching, 2008).

\section{Participants}

Students enrolled in an accounting course within the Business School at an American university were offered extra credit to participate in the study. A sample of 59 students registered for the study, from which 58 valid cases were obtained. One participant was removed from the data for excessively using a cell phone during the recordings. Sixty-six percent of the sample comprised of males, and the average age of the participants was 21 years. The ethnic breakdown was as follows: $69 \%$ Caucasian, 14\% African American, 12\% Asian, 2\% Hispanic, and 3\% self-categorized as "other."

The participants were randomly selected into one of the two counterbalancing conditions. Group 1 consisted of 30 participants, whereas Group 2 consisted of 28 participants. Group 1 viewed the High Arousal Recording before viewing the Neutral Arousal Recording, and Group 2 viewed the recordings in the reverse order. It was necessary to ensure that participants did not possess knowledge of the outcome prior to their participation. Three items were included to address their knowledge of the particular match to be viewed. Participants' knowledge of MMA was assessed using an adapted version of Flynn and Goldsmith's (1999) subjective consumer knowledge scale. General interest in MMA were measured with three items adapted from the Sport Interest Inventory (SII; Funk, Mahony, \& Ridinger, 2002). Previous 
consumptive behaviors pertaining to MMA events were measured using three items constructed to gauge the frequency that participants (1) watch, (2) read about, and (3) discuss MMA.

\section{Materials and Procedure}

The adapted PAD scale (Mehrabian \& Russell, 1974) was implemented to test the hypothesis that emotional arousal is significantly influenced by video type. The scale was adapted to remove the dominance dimension. The Pleasure-Arousal-Dominance (PAD) scale, is one of the most frequently implemented measures of consumer emotion. This scale extends the arousal-valence two-dimensional account by adding the construct dominance, which is defined as "the extent to which one feels unrestricted or free to act in a variety of ways" (Bearden et al., 2011, p. 310). The current study contributes to this literature in several regards. A direct manipulation of emotion was employed, and self-reported emotions were utilized solely as a manipulation check. This addresses concerns that the temporal and fluid state of emotional activity renders it prone to the biases of reflection (Davidson et al., 2003). Additionally, researchers have demonstrated that people are often quite unaware of their arousal states (Mattes \& Cantor, 1982; Stapel, 2008). The administered methodology was designed to control for extraneous factors and manipulate emotions, which circumvented a dependence upon interpretive and/or self-report measures.

The scale includes 12 semantic differentials; 6 items are used to measure both arousal and valence. Appendix A illustrates the items included in the PAD scale as well as the instructions presented to participants. Previous utilizations of the scale within a consumption context have demonstrated exceptional psychometric properties. Havlena and Holbrook (1986) were some of the first to use the PAD scale to examine the emotional outcomes of the consumer experience. The researchers reported adequate internal consistency $(\alpha=.79-.95)$.
Likewise, Holak and Havlena (1998) demonstrated high reliability measures for both arousal $(\alpha=.87)$ and valence $(\alpha=.95)$. Average variance explained (AVE) was also acceptable for both dimensions, as valence was found to explain $41 \%$ and arousal was found to explain $27 \%$ of the variance. Factor loadings ranged from $.80-.88$ for arousal and .78-.95 for valence. Additionally, Kwak et al. (2011) demonstrated the psychometric strength of the scale within a sport consumption context. The authors obtained adequate reliability $(\rho=.87-.93)$, factor loadings (.79-.95), and percentage of variance explained $(\mathrm{AVE}=70-86 \%)$.

The modified version of Mehrabian and Russell's (1974) PAD scale served two functions. First, it provided an assessment of the baseline emotional state of participants before viewing the recordings. Second, it was implemented as a check of the manipulation of emotional arousal and valence. The validity of self-report measures of emotion is largely questionable. People have been demonstrated to be quite unaware of their arousal states (Mattes \& Cantor, 1982), and emotions have been conceptualized as a rather unconscious process (Stapel, 2008). Furthermore, due to the above concerns, as well as the inherent limitations of self-report research, scores on the PAD scale were not utilized to make causal inferences.

The high arousal recording (HAR) consisted of the Light Heavyweight bout from the UFC event held in Las Vegas, Nevada in December of 2007 (referred to as "UFC 79"), which featured a match between Chuck Liddell and Wanderlei Silva. The match was considered by UFC as one of the most anticipated events of the league's history. Both fighters had won recent championships, and their matchup was promoted as the main event of UFC 79. The resultant contest between Liddell and Silva has been widely recognized as one of the most exciting MMA matches every. The fighters received a combined $\$ 100,000$ bonus for providing the "fight of the night" (UFC). Chiappetta (2009) ranked the fight as the eighth most memorable in UFC history. The match lasted the entirety of the three rounds (i.e., 
15 total minutes) without any stoppages. Despite the perceived competitiveness of the contest, Chuck Liddell unanimously won the decision, and two out of the three judges ruled that he won all three rounds. Although a highly competitive match is necessary for the manipulation of emotional arousal, a clear disparity between the performances of the fighters allows for a strong manipulation of emotional valence.

In order to provide a control comparison, a relatively uneventful contest was necessary. The 2008 Welterweight bout between Chris Wilson and Jon Fitch, known as "UFC 82," took place in Columbus, Ohio in March of 2008 and was utilized as the neutral arousal recording (NAR) in the current research. Very little anticipation preceded the match, as Chris Wilson was a relatively unknown replacement for an injured fighter (Akihiro Gono), and the contest was part of the UFC 82 undercard. Due to the slow-paced fighting style of Jon Fitch, only 62 strikes were landed (102 were landed in UFC 79 match). Additionally, $57 \%$ of the fight took place on the ground with Jon Fitch in the dominant position. The contest exhausted the entire 15 minutes without any clock stoppages, and Fitch won the bout by a unanimous decision.
Participants' arousal and valence scores were measured across three time intervals, including (1) prior to engaging in the study in order to establish an account of baseline emotional levels, (2) after viewing the HAR, and (3) after viewing the NAR. The order that the videos were viewed was counterbalanced across two between-subjects conditions.

\section{Results}

Participants entered Study 1 with baseline emotional conditions that did not significantly differ from neutrality. Neutrality is conceptualized as the midpoint of the 7-point PAD scale. A series of one-sample t-tests indicate that the means deriving from the 12 PAD items did not significantly differ from the midpoint. Additionally, the factor scores for each dimension indicated neutrality. The arousal score of 3.79 was not significantly below the midpoint, $t(57)=-1.20, p=.237$. Likewise, the valence score of 4.17 was not significantly above the midpoint, $t(57)=0.92, p=.361$. Table 2 illustrates the results of the one-sample t-tests.

As evidenced in Table 1, the inter-item correlations for the arousal dimension were acceptable, as Pearson's

Table 1. Study 1 Baseline Inter-item Correlations

\begin{tabular}{|c|c|c|c|c|c|c|c|c|c|c|c|c|}
\hline & A1 & A2 & A3 & A4 & A5 & A6 & V1 & V2 & V3 & V4 & V5 & V6 \\
\hline A1 & 1 & & & & & & & & & & & \\
\hline A2 & .580 & 1 & & & & & & & & & & \\
\hline A3 & .532 & .531 & 1 & & & & & & & & & \\
\hline A4 & .506 & .558 & .412 & 1 & & & & & & & & \\
\hline A5 & .468 & .477 & .624 & .453 & 1 & & & & & & & \\
\hline A6 & .603 & .459 & .730 & .438 & .635 & 1 & & & & & & \\
\hline V1 & .456 & .300 & .460 & .352 & .287 & .466 & 1 & & & & & \\
\hline V2 & .281 & .251 & .348 & .382 & .271 & .340 & 694 & 1 & & & & \\
\hline V3 & .209 & .231 & .168 & .332 & .004 & .119 & .571 & .654 & 1 & & & \\
\hline V4 & .269 & .012 & .242 & .044 & .024 & .091 & .526 & .481 & .609 & 1 & & \\
\hline V5 & .337 & .160 & .188 & .129 & .151 & .208 & .440 & .645 & .399 & .396 & 1 & \\
\hline V6 & .322 & .264 & .395 & .284 & .192 & .328 & .657 & .728 & .658 & .505 & .507 & 1 \\
\hline $\mathbf{M}$ & 3.78 & 3.71 & 3.95 & 3.79 & 3.86 & 3.67 & 4.33 & 4.28 & 4.09 & 4.17 & 4.07 & 4.05 \\
\hline SD & 1.57 & 1.57 & 1.71 & 1.78 & 1.75 & 1.74 & 1.63 & 1.83 & 1.67 & 1.80 & 1.76 & 1.69 \\
\hline
\end{tabular}


Table 2. Study 1 Baseline Tests of Neutrality

\begin{tabular}{ccccc}
\hline & & \multicolumn{3}{c}{ 95\% Confidence Interval } \\
Items & $\boldsymbol{t}$ & $\boldsymbol{p}$ & Lower & Upper \\
\hline A1 & -1.089 & .281 & -0.64 & 0.19 \\
A2 & -1.424 & .160 & -0.71 & 0.12 \\
A3 & -0.230 & .819 & -0.50 & 0.40 \\
A4 & -0.888 & .378 & -0.67 & 0.26 \\
A5 & -0.600 & .551 & -0.60 & 0.32 \\
A6 & -1.433 & .157 & -0.79 & 0.13 \\
\cline { 2 - 5 } Factor Score & $-\mathbf{- 1 . 1 9 5}$ & .237 & $-\mathbf{0 . 5 5}$ & $\mathbf{0 . 1 4}$ \\
\hline V1 & 1.534 & .131 & -0.10 & 0.76 \\
V2 & 1.223 & .227 & -0.19 & 0.77 \\
V3 & 0.394 & .695 & -0.35 & 0.52 \\
V4 & 0.730 & .468 & -0.30 & 0.65 \\
V5 & 0.299 & .766 & -0.39 & 0.53 \\
V6 & 0.233 & .817 & -0.39 & 0.50 \\
\cline { 2 - 5 } Factor Score & $\mathbf{0 . 9 2 0}$ & .361 & -0.20 & $\mathbf{0 . 5 3}$ \\
\hline \hline
\end{tabular}

Note: Table includes one-sample t-test results. $95 \%$ confidence interval is based on the difference between the mean and the midpoint of the scale.

Table 3. Study 1 Mean Comparisons across Counterbalancing Conditions

\begin{tabular}{ccccc}
\hline \hline & & \multicolumn{3}{c}{ 95\% Confidence Interval } \\
Items & $\boldsymbol{t}$ & $\boldsymbol{p}$ & Lower & Upper \\
\hline A1 & 1.399 & .167 & -1.390 & 0.247 \\
A2 & 1.041 & .302 & -1.253 & 0.396 \\
A3 & 0.068 & .946 & -0.940 & 0.878 \\
A4 & 1.157 & .252 & -1.469 & 0.393 \\
A5 & 0.920 & .362 & -0.500 & 1.347 \\
A6 & 1.239 & .220 & -1.476 & 0.348 \\
\cline { 2 - 5 } Factor Score & $\mathbf{0 . 8 2 0}$ & .416 & $-\mathbf{0 . 9 8 1}$ & $\mathbf{0 . 4 1 1}$ \\
\hline V1 & 0.293 & .771 & -0.989 & 0.737 \\
V2 & 0.256 & .799 & -1.093 & 0.845 \\
V3 & 0.878 & .384 & -1.265 & 0.494 \\
V4 & 0.170 & .866 & -1.036 & 0.874 \\
V5 & 1.059 & .294 & -1.411 & 0.435 \\
V6 & 0.533 & .596 & -0.657 & 1.133 \\
\cline { 2 - 5 } Factor Score & $\mathbf{0 . 4 4 4}$ & .659 & $-\mathbf{0 . 8 9 3}$ & $\mathbf{0 . 5 6 9}$ \\
\hline \hline
\end{tabular}

Note: Table includes independent sample t-test results. $95 \%$ confidence interval is based on the difference between group means. correlation coefficient ranged from $r=0.412$ to $r=$ 0.730 . The valence dimension demonstrated similarly acceptable coefficients, which ranged from $r=0.396$ to $r=0.728$. Inter-dimensional relationships (i.e., arousal items associated with valence items), which are highlighted in red in Table 1, yielded a mixture of correlations, ranging from $r=0.004$ to $r=0.466$. The average inter-dimensional correlation was small but noteworthy $(r=0.247)$. This reinforces the necessity of implementing a methodology that experimentally controls for one dimension while examining the other. These results are intuitive as one would expect that moderately positive levels of arousal are perceived as pleasant. Thus, a positive correlation between arousal and valence is expected. Indeed, the factor correlation between the dimensions was significant $(r=.393, p=$ $.002)$.

It is important to demonstrate that the two counterbalancing conditions were equivalent across both emotional dimensions prior to engaging in the study, as the two groups represent distinct data collection sessions. Group 1 (HAR then NAR) demonstrated an overall arousal factor score of $M=3.66(S D=1.37)$, which was not significantly different from the overall arousal factor score obtained from Group 2 of $M=3.94$ $(S D=1.26), t(56)=0.820, p=.416$. Likewise, the overall valence factor score for Group 1 of $M=4.09$ $(S D=1.44)$ was not significantly different from the overall valence factor score for Group 2 of $M=4.25$ $(S D=1.33), t(56)=0.444, p=.659$. Additionally, based on a series of independent t-tests, the two groups did not significantly differ across any of the 12 PAD items (see Table 3).

The PAD scale was again administered following the viewing of the HAR video in order to examine the influence of this stimulus upon emotional arousal and valence. Table 4 depicts the resultant means and inter-item correlations. As evidenced in the table, all intra-dimensional correlations were significant at the .01 level. The arousal inter-item correlations ranged from $\mathrm{r}=.364$ to $\mathrm{r}=.685$, and the valence inter-item 
Table 4. Study 1 HAR Inter-item Correlations

\begin{tabular}{|c|c|c|c|c|c|c|c|c|c|c|c|c|}
\hline & A1 & A2 & A3 & A4 & A5 & A6 & V1 & V2 & V3 & V4 & V5 & V6 \\
\hline A1 & 1 & & & & & & & & & & & \\
\hline A2 & .635 & 1 & & & & & & & & & & \\
\hline A3 & .685 & .595 & 1 & & & & & & & & & \\
\hline A4 & .431 & .631 & .601 & 1 & & & & & & & & \\
\hline A5 & .556 & .460 & .653 & .441 & 1 & & & & & & & \\
\hline A6 & .605 & .481 & .507 & .364 & .635 & 1 & & & & & & \\
\hline V1 & .085 & .162 & .164 & .084 & .410 & -.033 & 1 & & & & & \\
\hline V2 & .147 & .214 & .144 & .074 & .137 & -.031 & .598 & 1 & & & & \\
\hline V3 & .056 & .107 & .012 & .039 & -.007 & -.080 & .439 & .628 & 1 & & & \\
\hline V4 & .121 & -.007 & .099 & -.217 & -.028 & .073 & .465 & .424 & .452 & 1 & & \\
\hline V5 & .136 & .108 & .061 & .018 & .086 & -.007 & .653 & .629 & .586 & .444 & 1 & \\
\hline V6 & .194 & .104 & .191 & .008 & .099 & .113 & .468 & .580 & .464 & .614 & .432 & 1 \\
\hline $\mathbf{M}$ & 5.41 & 5.17 & 5.36 & 5.24 & 5.07 & 5.26 & 4.28 & 4.26 & 4.38 & 4.21 & 4.28 & 4.12 \\
\hline SD & 1.57 & 1.67 & 1.65 & 1.68 & 1.59 & 1.56 & 1.77 & 1.74 & 1.79 & 1.68 & 1.78 & 1.81 \\
\hline
\end{tabular}

Table 5. Study 1 HAR Counterbalancing Comparisons

\begin{tabular}{|c|c|c|c|c|c|c|c|c|}
\hline & & A1 & A2 & A3 & A4 & A5 & A6 & $\begin{array}{c}\text { Arousal } \\
\text { Factor }\end{array}$ \\
\hline \multirow{4}{*}{$\begin{array}{l}\text { Arousal } \\
\text { Items }\end{array}$} & Group 1 & 5.60 & 5.50 & 5.73 & 5.43 & 5.10 & 5.27 & 5.44 \\
\hline & Group 2 & 5.21 & 4.82 & 4.96 & 5.04 & 5.04 & 5.25 & 5.05 \\
\hline & $t$ & 0.926 & 1.553 & 1.782 & 0.900 & 0.153 & 0.40 & 1.158 \\
\hline & $p$ & .359 & .127 & .081 & .372 & .879 & .968 & .252 \\
\hline \multirow{5}{*}{ Valence Items } & & V1 & V2 & V3 & V4 & V5 & V6 & $\begin{array}{l}\text { Valence } \\
\text { Factor }\end{array}$ \\
\hline & Group 1 & 4.33 & 4.70 & 4.53 & 4.27 & 4.30 & 4.47 & 4.43 \\
\hline & Group 2 & 4.21 & 3.79 & 4.21 & 4.14 & 4.25 & 3.75 & 4.05 \\
\hline & $t$ & 0.255 & $2.052^{*}$ & 0.677 & 0.278 & 0.106 & 1.527 & 1.036 \\
\hline & $p$ & .800 & .045 & .501 & .782 & .916 & .132 & .305 \\
\hline
\end{tabular}

Note: Group 1 viewed the HAR video prior to viewing the NAR video. Group 2 engaged in the study in the reverse order.

correlations ranged from $\mathrm{r}=.424$ to $\mathrm{r}=.653$. Interestingly, the intra-dimensional correlations were each insignificant, with an average coefficient of $|\mathrm{r}|=$ .092, indicating that an external emotional stimulus may diminish the arousal-valence relationship. Indeed, the singular impact of the external stimulus upon only emotional arousal may override the causal link between the two dimensions.

Arousal and valence scores for Group 1 (i.e., HAR then NAR) were compared to Group 2 (i.e., NAR then HAR). Table 5 summarizes the results of a series of independent samples t-tests examining the potential of ordering effects. The counterbalancing conditions were equivalent across all items, with the exception of $\mathrm{V} 2$, $t(56)=2.052, p=.045$. Regarding this item, the mean for Group $1(M=4.70)$ was significantly more positive than the mean for Group $2(M=3.79)$. This is likely a spurious finding, as all other comparisons were found 
Table 6. Study 1 Post-HAR Comparisons to Baseline Conditions

\begin{tabular}{|c|c|c|c|c|c|c|c|c|}
\hline & & A1 & A2 & A3 & A4 & A5 & A6 & $\begin{array}{c}\text { Arousal } \\
\text { Factor }\end{array}$ \\
\hline \multirow{4}{*}{$\begin{array}{l}\text { Arousal } \\
\text { Items }\end{array}$} & Baseline & 3.78 & 3.71 & 3.95 & 3.79 & 3.86 & 3.67 & 3.79 \\
\hline & Post-HAR & 5.41 & 5.17 & 5.36 & 5.24 & 5.07 & 5.26 & 5.25 \\
\hline & $t$ & $6.636^{* *}$ & $6.074 * *$ & $5.021 * *$ & $4.758 * *$ & $3.932 * *$ & $6.013^{* *}$ & $6.988 * *$ \\
\hline & $p$ & $<.001$ & $<.001$ & $<.001$ & $<.001$ & $<.001$ & $<.001$ & $<.001$ \\
\hline \multirow{5}{*}{ Valence Items } & & V1 & V2 & V3 & V4 & V5 & V6 & $\begin{array}{c}\text { Valence } \\
\text { Factor }\end{array}$ \\
\hline & Baseline & 4.33 & 4.29 & 4.09 & 4.17 & 4.07 & 4.05 & 4.17 \\
\hline & Post-HAR & 4.28 & 4.26 & 4.38 & 4.21 & 4.28 & 4.12 & 4.25 \\
\hline & $t$ & 0.245 & 0.174 & 1.456 & 0.138 & 0.807 & 0.359 & 0.607 \\
\hline & $p$ & .807 & .863 & .151 & .891 & .423 & .721 & .546 \\
\hline
\end{tabular}

Note: Table contains comparisons between baseline means and post-HAR means as well as corresponding paired samples t-tests. ** denotes significance at the .01 level.

Table 7. Study 1 NAR Counterbalancing Comparisons

\begin{tabular}{|c|c|c|c|c|c|c|c|c|}
\hline & & A1 & A2 & A3 & A4 & A5 & A6 & $\begin{array}{r}\text { Arousal } \\
\text { Factor } \\
\end{array}$ \\
\hline \multirow{4}{*}{$\begin{array}{l}\text { Arousal } \\
\text { Items }\end{array}$} & Group 1 & 4.20 & 3.40 & 3.63 & 3.60 & 4.13 & 3.70 & 3.78 \\
\hline & Group 2 & 3.29 & 3.14 & 3.39 & 3.64 & 3.25 & 3.32 & 3.34 \\
\hline & $t$ & $2.095^{*}$ & 0.585 & 0.503 & 0.095 & 1.903 & 0.857 & 1.357 \\
\hline & $p$ & .041 & .561 & .617 & .925 & .062 & .395 & .180 \\
\hline \multirow{5}{*}{$\begin{array}{l}\text { Valence } \\
\text { Items }\end{array}$} & & V1 & V2 & V3 & V4 & V5 & V6 & $\begin{array}{l}\text { Valence } \\
\text { Factor }\end{array}$ \\
\hline & Group 1 & 4.07 & 4.00 & 4.37 & 3.87 & 4.13 & 3.63 & 4.01 \\
\hline & Group 2 & 3.93 & 3.79 & 4.21 & 3.79 & 3.96 & 3.68 & 3.89 \\
\hline & $t$ & 0.287 & 0.462 & 0.320 & 0.171 & 0.380 & 0.104 & 0.330 \\
\hline & $p$ & .775 & .646 & .750 & .865 & .705 & .917 & .743 \\
\hline
\end{tabular}

Note: Table contains counterbalancing group means and corresponding independent samples t-tests. * denotes significance at the .05 level. Group 1 viewed the HAR video prior to viewing the NAR video. Group 2 engaged in the study in the reverse order.

to be insignificant, including the valence factor score comparison across groups, $t(56)=1.036, p=.305$. Additionally, the arousal dimension is of particular interest, as the video stimuli are designed specifically to manipulate emotional arousal. All arousal items were equivalent across counterbalancing groups, including the arousal factor score, $t(56)=1.158, p=.252$. counterbalancing conditions.

The baseline arousal factor score was $M=3.79$ (SD
= 1.32), and this increased to $M=5.25(S D=1.27)$. The difference across these factor scores was significant, $t(57)=6.988, p<.001$. These findings indicate that the HAR stimulus had a robust positive influence upon emotional arousal. Valence conditions, on the other hand, did not differ as a result of the HAR manipulation. The baseline valence factor score $(M=4.17$; $S D=1.38)$ was statistically equivalent to the score following the viewing of the HAR $(M=4.25 ; S D=1.37)$. 
Table 8. Study 1 Repeated Measures Mean Comparisons across Video Manipulation Conditions

\begin{tabular}{|c|c|c|c|c|c|c|c|c|c|c|c|c|c|c|}
\hline & \multicolumn{2}{|c|}{$\overline{\mathrm{A} 1}$} & \multicolumn{2}{|c|}{ A2 } & \multicolumn{2}{|c|}{ A3 } & \multicolumn{2}{|c|}{ A4 } & \multicolumn{2}{|c|}{ A5 } & \multicolumn{2}{|c|}{ A6 } & \multicolumn{2}{|c|}{ Factor } \\
\hline & $\boldsymbol{M}$ & $S D$ & $M$ & $S D$ & $\boldsymbol{M}$ & $S D$ & $M$ & $S D$ & $M$ & $S D$ & $M$ & $S D$ & $M$ & $S D$ \\
\hline B & 3.9 & 1.6 & 3.7 & 1.6 & 4.0 & 1.7 & 3.8 & 1.8 & 3.9 & 1.8 & 3.7 & 1.7 & 3.8 & 1.3 \\
\hline NAR & 3.8 & 1.7 & 3.3 & 1.7 & 3.5 & 1.8 & 3.6 & 1.7 & 3.7 & 1.8 & 3.5 & 1.7 & 3.6 & 1.2 \\
\hline HAR & 5.4 & 1.6 & 5.2 & 1.7 & 5.4 & 1.7 & 5.2 & 1.7 & 5.1 & 1.6 & 5.3 & 1.6 & 5.3 & 1.3 \\
\hline$F$ & \multicolumn{2}{|c|}{$34.638^{* *}$} & \multicolumn{2}{|c|}{$30.207^{* *}$} & \multicolumn{2}{|c|}{$24.247 * *$} & \multicolumn{2}{|c|}{$20.039 * *$} & \multicolumn{2}{|c|}{$12.846^{* *}$} & \multicolumn{2}{|c|}{$30.767 * *$} & \multicolumn{2}{|c|}{$49.329 * *$} \\
\hline$p$ & \multicolumn{2}{|c|}{.000} & \multicolumn{2}{|c|}{.000} & \multicolumn{2}{|c|}{.000} & \multicolumn{2}{|c|}{.000} & \multicolumn{2}{|c|}{.000} & \multicolumn{2}{|c|}{.000} & \multicolumn{2}{|c|}{.000} \\
\hline & \multicolumn{2}{|c|}{$\mathrm{V} 1$} & \multicolumn{2}{|c|}{$\mathrm{V} 2$} & \multicolumn{2}{|c|}{$\mathrm{V} 3$} & \multicolumn{2}{|c|}{ V4 } & \multicolumn{2}{|c|}{ V5 } & \multicolumn{2}{|c|}{ V6 } & \multicolumn{2}{|c|}{ Factor } \\
\hline & $M$ & $S D$ & $M$ & $S D$ & $M$ & $S D$ & $M$ & $S D$ & $M$ & $S D$ & $M$ & $S D$ & $M$ & $S D$ \\
\hline B & 4.3 & 1.6 & 4.3 & 1.8 & 4.1 & 1.7 & 4.2 & 1.8 & 4.1 & 1.8 & 4.1 & 1.7 & 4.2 & 1.4 \\
\hline NAR & 4.0 & 1.8 & 3.9 & 1.8 & 4.3 & 1.8 & 3.8 & 1.8 & 4.1 & 1.7 & 3.7 & 1.6 & 4.0 & 1.4 \\
\hline HAR & 4.3 & 1.8 & 4.3 & 1.7 & 4.4 & 1.8 & 4.2 & 1.7 & 4.3 & 1.8 & 4.1 & 1.8 & 4.3 & 1.4 \\
\hline$F$ & \multicolumn{2}{|c|}{1.077} & \multicolumn{2}{|c|}{1.973} & \multicolumn{2}{|c|}{0.859} & \multicolumn{2}{|c|}{1.211} & \multicolumn{2}{|c|}{0.500} & \multicolumn{2}{|c|}{$2.244^{\mathrm{a}}$} & \multicolumn{2}{|c|}{1.767} \\
\hline$p$ & & & & & & & & & & & & & & \\
\hline
\end{tabular}

Note: This table displays the results of repeated measures ANOVAs across the three time intervals of this study. * denotes significance at the .05 level. ** denotes significance at the .01 level.

${ }^{a}$ Due to a violation of the sphericity assumption, the Greenhouse-Geisser adjusted degrees of freedom and corresponding p-value are reported.

Additionally, there were zero significant differences across the individual valence items due to the HAR manipulation.

The primary objective of Study 1 was to demonstrate that the emotional arousal elicited by the NAR is approximately neutral, and the arousal levels evoked by the HAR would be significantly more positive. Therefore, the PAD was administered once more following the viewing of the NAR. Once again, it is necessary to test for group and ordering effects across the two counterbalancing conditions. As demonstrated in the table, Group 1 demonstrated a general higher level of arousal, though only one significant difference was obtained across the six items (A1). This may be due to an ordering effect; Group 1 engaged in the NAR phase of the study after the HAR phase, whereas Group 2 engaged in the NAR phase before the HAR phase. Therefore, there may have been a residual effect of arousal carrying over from the HAR phase for Group 1 that did not take place in Group 2. However, this only culminated in one inter-item disparity, and the groups did not display significantly different arousal factor scores, $t(56)=1.357, p=180$. Regarding the valence dimension, zero significant differences were obtained across the six items, including the valence factor score, $t(56)=0.330, p=.743$.

All intra-dimensional correlations were significant, ranging from $r=.304$ to $r=.570$ for the arousal items and $r=.384$ to $r=.716$ for the valence items. On the other hand, the average inter-dimensional correlation was negligible $(|\mathrm{r}|=.116)$, once again suggesting that the arousal-valence relationship is somewhat mitigated by external stimuli.

A consistent pattern was obtained for each analysis of the arousal items. First, the assumption of sphericity was supported, indicating that the variances of the differences between groups were statistically equivalent across all possible combinations. $\chi^{2}(2)$ ranged from 0.257 to 4.758 , each of which was insignificant at the .05 level. Second, each ANOVA model was significant at the .01 level (see Table 8 for F-statistics and corresponding $\mathrm{p}$-values), including the arousal factor score, $F(2,114)=49.329, p<.01$. Eta-squared ranged from .184 to .464 . Third, Fisher's least significant 
Table 9. Study 2 Commercial Stimuli Emotion, Familiarity, and POR Means

\begin{tabular}{|c|c|c|c|c|c|c|}
\hline \multirow{16}{*}{ Positive } & Code & Brand & Valence & Arousal & Familianity & POR \\
\hline & POS1 & Dairy Queen & 5.87 & 4.45 & 2.71 & .46 \\
\hline & POS2 & Chevrolet & 5.86 & 5.34 & 2.33 & .50 \\
\hline & POS3 & Folgers & 5.78 & 3.77 & 2.73 & .39 \\
\hline & POS4 & Old Spice & 5.74 & 5.13 & 3.85 & .69 \\
\hline & POS5 & Geico & 5.72 & 4.75 & 4.05 & .54 \\
\hline & POS6 & Crystal Light & 5.43 & 3.82 & 2.21 & .27 \\
\hline & POS7 & Red Lobster & 5.42 & 3.41 & 2.74 & .23 \\
\hline & POS8 & Entergy & 5.32 & 3.25 & 1.50 & .12 \\
\hline & POS9 & Budweiser & 5.08 & 4.35 & 3.09 & .41 \\
\hline & POS10 & Pur & 5.01 & 3.27 & 2.72 & .12 \\
\hline & POS11 & Dentyne & 4.99 & 3.23 & 1.82 & .21 \\
\hline & POS12 & MidFirst Bank & 4.99 & 2.93 & 1.68 & .11 \\
\hline & POS13 & $\mathrm{BP}$ & 4.91 & 3.35 & 1.75 & .30 \\
\hline & POS14 & Avis & 4.86 & 4.13 & 2.47 & .69 \\
\hline & POS15 & Aussie & 4.77 & 3.31 & 2.14 & .37 \\
\hline \multirow{9}{*}{ Neutral } & Code & Brand & Valence & Arousal & Familiarity & POR \\
\hline & NEU1 & Buick & 4.63 & 3.63 & 2.06 & .29 \\
\hline & NEU2 & Gillette & 4.58 & 3.56 & 3.13 & .23 \\
\hline & NEU3 & Aleve & 4.56 & 2.51 & 2.46 & .30 \\
\hline & NEU4 & Toyota & 4.50 & 4.25 & 2.79 & .41 \\
\hline & NEU5 & $B M W$ & 4.47 & 4.14 & 1.93 & .35 \\
\hline & NEU6 & Ask.com & 4.40 & 3.15 & 1.89 & .16 \\
\hline & NEU7 & Boost Mobile & 4.25 & 3.91 & 2.69 & .13 \\
\hline & NEU8 & Jobsite & 4.18 & 3.86 & 1.35 & .20 \\
\hline \multirow{10}{*}{ Negative } & Code & Brand & Valence & Arousal & Familianity & POR \\
\hline & NEG1 & Excedrin & 3.94 & 4.23 & 1.66 & .31 \\
\hline & NEG2 & Mirror's Edge & 3.71 & 4.77 & 2.08 & .28 \\
\hline & NEG3 & Shelter Project & 3.65 & 3.39 & 1.32 & .42 \\
\hline & NEG4 & Pedigree & 3.35 & 4.36 & 2.16 & .45 \\
\hline & NEG5 & Child Hunger & 3.34 & 4.43 & 2.29 & .33 \\
\hline & NEG6 & Endwar & 2.92 & 4.41 & 1.86 & .32 \\
\hline & NEG7 & Drugfree.org & 2.27 & 4.97 & 2.13 & .51 \\
\hline & $N E G 8$ & Texting/Driving & 2.19 & 5.41 & 2.90 & .35 \\
\hline & NEG9 & Methamphetamine & 1.83 & 6.34 & 1.69 & .72 \\
\hline
\end{tabular}

difference (LSD) post-hoc analyses demonstrated that level of arousal (as measured by each arousal item of the PAD) was significantly higher following the HAR than either following the NAR or baseline arousal. Additionally, the post-hoc analyses indicate that arousal levels following the NAR were equivalent to baseline levels; the NAR appeared to have no impact on level of arousal. This is an important finding, as the NAR represents the treatment issued to the neutral arousal condition $\left(\mathrm{A}^{0}\right)$ of the main study.

In direct contrast to the impact of the video manipulation upon participant arousal, the videos did not have an influence upon valence as measured by any of the valence items. Each ANOVA model was 
insignificant at the .05 level, including the valence factor score, $F(2,114)=1.767, p=.175$. Table 8 depicts the mean comparisons across each of the items and factor scores, as well as the corresponding F-statistics and $p$-values.

\section{Study 2}

The purpose of Study 2 was to develop a procedure for measuring the emotional valence of commercial stimuli.

\section{Participants}

Students enrolled in a senior-level finance course at an American university were offered extra credit to participate in an online study. An a priori power analysis was conducted to obtain the overall and cell sample sizes necessary to achieve the level of power (0.8) recommended by Cohen (1992) for a one-way analysis of variance (ANOVA) across three group means. A large effect size was assumed (i.e., $\mathrm{f}=0.4$; Cohen, 1977) and alpha was set to 0.5. Using G*Power 3.0 (Faul et al., 2007), it was determined that 66 participants $(n=22)$ were necessary to meet Cohen's aforementioned standard. The online study was active for 8 days. During this time, 126 participants across 21 majors enrolled in the study, resulting in 111 valid cases. Thirty-one percent of the sample was comprised of males, and the average age of the participants was 21 years. The average duration for this task was 43 minutes, ranging from 27 minutes to 102 minutes.

\section{Materials and Procedure}

A panel of researchers was selected to issue a preliminary, subjective review of the commercial stimuli prior to their implementation into the study consisted of three members. The panel was comprised of two academic researchers within the field of Sport Management as well as two within the field of Marketing. We provided the panel with a total of 51 commercials. The panel was tasked with accepting or rejecting each of these items. Of this set of stimuli, 32 commercials were selected by the panel for inclusion.

Study 2 was completed online. A hyperlink was distributed which directed participants to a webpage containing video of a randomized sequence of the 30 aforementioned commercial advertisements. After each individual advertisement was viewed, participants rated (1) the extent to which the video elicited positive/negative feelings, (2) the extent to which the video elicited excitement, and (3) the whether the participant has previously seen the commercial. These ratings were followed by an unannounced test of free recall. Presentation order of the stimuli was randomized to alleviate concerns of primacy/recency effects influencing POR (Murdock, 1962; Nairne, 1988).

The adapted PAD scale (Mehrabian \& Russell, 1974) was implemented to test the hypothesis that emotional arousal is significantly influenced by video type. Participants' arousal and valence scores were measured across three time intervals, including (1) prior to engaging in the study in order to establish an account of baseline emotional levels, (2) after viewing the HAR, and (3) after viewing the NAR. The order that the videos were viewed was counterbalanced across two between-subjects conditions

\section{Results}

The overall affective tone (i.e., valence) of the commercial stimuli was rated as slightly positive $(M$ $=4.45$ ), which is significantly more positive than the midpoint on the 7-point valence scale (CI: 4.51, 4.40). This indicates that participants may have been positively biased in their valence ratings.

Regarding the $\mathrm{V}^{+}$commercials, items POS1, POS2, POS3, and POS5 were selected for the study. With one exception, these were the most positively rated commercials within the overall item set. POS4 was omitted due to an exceedingly high POR score (.69). The valence scores of the selected items are statistically 
equivalent $(F=.393 ; p=.758)$. Binary logistic regression analysis was conducted to determine if POR scores significantly differed across items. The results from the omnibus test of model coefficients led me to conclude the variance in the POR outcome variable was not predicted by commercial item at above chance levels $\left(\chi^{2}=5.851 ; p=.119\right)$. Finally, to determine if the recall of one item actively prompts the recall of another item, phi correlation coefficients were calculated across the POR scores for each item. This was not considered to be a concern, as there were zero coefficients that exceeded 0.70 .

Regarding the $\mathrm{V}^{0}$ commercials, items NEU2, NEU3, NEU4, and NEU5 were selected. With one exception, these were the items with valence scores that most approximated the grand mean (4.45), as all four items were within .13 of this standard $(S D=1.66)$. Although each of these items were rated more positively than the grand mean, these differences were not found to be significant based on a one-sample t-test analyzing the most extreme score (i.e., NEU2; $t=1.177, p=.242$ ). NEU6 was omitted due to an exceedingly low POR score (.16). In place of NEU6, the item labeled NEU2 was selected because it is the next closest item to the grand mean. In other words, NEU1, NEU7, and NEU8 were considered "less neutral".

The valence scores of the selected items are statistically equivalent $(F=.229 ; p=.876)$. Based on the binary logistic regression analysis, it was evident that variance in POR scores was significantly predicted by commercial item $\left(\chi^{2}=5.388 ; p=.002\right)$. We concluded from this finding that POR scores significantly varied across the items, ranging from .23 to .41 . Nevertheless, these items were selected to avoid contaminating the valence manipulation. Although the findings of this study indicate that POR scores may vary within the $\mathrm{V}^{0}$ item set, this is not deemed to be a concern as these effects can be equalized across experimental conditions in follow-up studies. Finally, to determine if the recall of one item actively prompts the recall of another item, phi correlation coefficients were calculated across the POR scores for each item. This was not considered to be a concern, as there were zero coefficients that exceeded 0.70 .

Regarding the $\mathrm{V}^{-}$commercials, items NEG4, NEG5, NEG7, and NEG8 were selected. With two exceptions, these were the most negatively rated commercials within the overall item set. NEG9 was omitted due to exceedingly high scores for arousal $(M=6.34$ on the 7-point scale) and POR (.72). NEG6 was omitted due to an abnormally low familiarity score $(M=1.86$ on the 7-point scale). Although the selected items, therefore, do not represent the most negatively rated commercials within the item set of this study, each of the $\mathrm{V}$ - items were rated as significantly more negative than the grand mean $(t=-7.113 ; p=.000)$ and the midpoint of the scale $(t=-4.200 ; p=.000)$.

The valence scores of the selected items were not found to be statistically equivalent $(F=18.876 ; p=$ $.000)$. NEG7 and NEG8 were rated significantly more negative than NEG4 and NEG5. NEG7 was not significantly different from NEG8 $(\mathrm{t}=.081 ; \mathrm{p}=.700)$. Likewise, NEG4 was not significantly different from NEG5 $(\mathrm{t}=.009 ; \mathrm{p}=.966)$. These results indicate that it may be more accurate to conceptualize NEG7 and NEG8 as an "extremely negative" item category. This allows for an additional gradient of analysis within the main study regarding the impact of negative valence upon retrieval processes. Binary logistic regression analysis was conducted to determine if POR scores significantly differed across items. Based on the omnibus test of model coefficients, it was concluded that the variance in the POR outcome variable was not predicted by commercial item at above chance levels $\left(\chi^{2}=0.314 ; p=.575\right)$. Next, to determine if the recall of one item actively prompts the recall of another item, phi correlation coefficients were calculated across the POR scores for each item. This was not considered to be a concern, as there were zero coefficients that exceeded 0.70 .

Finally, it was necessary to demonstrate that the commercials within each item category $\left(\mathrm{V}^{+}, \mathrm{V}^{0}\right.$, and $\left.\mathrm{V}^{-}\right)$ 
were rated significantly different across the valence dimension. This was done by simply conducting a one-way ANOVA analyzing the valence scores for the extreme items within each category. In other words, the mean valence score for the POS5, NEU2, NEU5, and NEG4 items were examined. The ANOVA results provide confirmation of the hypothesis that the valence scores significantly differed across item categories $(F$ $=61.522 ; p=.000)$. Post-hoc testing1) indicated that the extreme items significantly differed across categories. For instance, the most positively rated item within the $\mathrm{V}^{0}$ category (NEU2) was rated significantly lower than the least positively rated item within the $\mathrm{V}^{+}$ category (POS5; $\Delta M=1.144, p=.000)$.

\section{Discussion}

In Study 1, the PAD scale was implemented to empirically establish the role of emotional arousal during live sports consumption. In a repeated measures study, a sample of 58 students (1) provided an account of their baseline emotions, (2) reported their emotions during a viewing of one of the experimental videos (i.e., HAR or NAR), and (3) reported their emotions during a viewing of the other video. The results demonstrated a significant difference in emotional arousal due to the manipulation. Emotional valence was impervious to the viewing of the videos and, thereby, remained consistent with baseline levels. The correlational structure of the items varied slightly across intervals, as the manipulation may have weakened the arousal-valence relationship. Overall, this study supported the NAR as an adequate representation of control conditions, and the HAR was empirically demonstrated to enhance levels of emotional arousal without influencing emotional valence.

In Study 2, a total of 51 commercial stimuli were examined by a panel of researchers, and 32 items were viewed by a sample 111 students. The participants

1) Fisher's Least Significant Difference (LSD) analysis was implemented. provided valence, arousal, familiarity, and POR scores for each of the items, and this information was used to create three sets of valenced stimuli (i.e., positive, negative, and neutral). For each set of stimuli, differences in arousal, familiarity, and POR scores were minimized, whereas valence differences were maximized. A total of 12 commercials were derived from this study.

Taken together, these studies combine to satisfy two overarching objectives. First, they empirically establish the impact that the consumption of televised sports may have upon consumer emotional arousal. This is pertinent as emotional arousal has a well-documented impact upon various cognitive (e.g., attention memory, and attitudes) and behavioral outcomes that sport managers often track. Second, they provide a protocol for selecting commercial and video stimuli that may be implemented in experimental manipulations of consumer emotion. In order to continue researching the emotion-cognition-behavior exchange in a live sports setting, materials with documented baseline emotional qualities will be necessary.

The current study contributes to several streams of research. The affective sciences literature has primarily focused on other components of affect (e.g., moods and feelings) due to an inability to evoke emotional behavior in a controlled setting (Davidson et al., 2003). Affect is often manipulated through the utilization of techniques such as music (Alpert \& Alpert, 1990), written passages (Bower, 1981), and pictures (Schiffenbauer, 1974). This study involved a manipulation of affect within a context known to engender extreme levels of emotional volatility (Duffy, 2004). Additionally, an experimental methodology was utilized to implement conditions known to engender an emotional reaction.

The cognitive science literature, on the other hand, is comprised of a very broad and multifarious theoretical background. The emotion-memory relationship has been examined from several perspectives, and at least four theoretical predictions have been issued. First, 
researchers have demonstrated that the arousing nature of emotions improves cognitive functioning in a similar fashion to the enhancing influence of caffeine (Cotton, 2006). Alternatively, evidence exists supporting a negative emotion-memory relationship. One explanation is that emotion detracts from the cognitive resources depended upon for normal memory functioning (Conway \& Engle, 1994). Researchers have also suggested that emotions activate an evolved instinct to focus attention upon central stimuli and suppress the processing of peripheral information (e.g., marketing stimuli; Dukas, 2009). Finally, models of human memory have portrayed this cognitive process as state dependent (Eich, 1995; Godden \& Baddeley, 1975). The present study contributes to the cognitive sciences literature by implementing a design that tests all four of the aforementioned theoretical predictions.

Some research within the consumer behavior domain has directly examined the influence of affective processes upon memory for marketing stimuli (Mattes \& Cantor, 1982; Scott \& Goff, 1988). However, the extent to which emotion has been observed is questionable. One contribution from this research to the consumer behavior literature is examining consumer memory for various types of marketing stimuli within a context conducive for emotional consumption.

Finally, a contribution is made to a rather undeveloped body of literature pertaining to sport consumer emotions. Sport marketing researchers have examined the emotional process in a very limited capacity. As a whole, this area of study has generally been based on self-report and recalled measures of emotion. Furthermore, emotions as a causal agent dictating consumer responses has been largely neglected within the sport marketing literature. There is almost a complete absence of research examining the emotion-memory relationship, specifically. The studies that do exist have failed to (1) experimentally examine the relationship in order provide strong evidence of causality, (2) examine the moderating influence of stimulus type, and (3) issue a theoretical account for the influence of emotion upon memory. This study addresses each of these voids.

\section{Practical Implications}

Sport marketers are faced with the challenge of adapting to a rapidly evolving climate. Customers are demanding increased access, and impersonal advertising is gradually falling out of favor. Marketing budgets are adjusting to these shifts, as resources are increasingly allocated toward inbound marketing approaches. That is, rather than reaching out to consumers through traditional advertising methods (i.e., outbound marketing), marketers are generating interesting content that attracts customers to the brand. This goal is accomplished by creating accessible and useful websites, instilling a social media presence, facilitating mobile access, dispersing secondary web content (e.g., blogs and podcasts), and enhancing search engine optimization (SEO). Research has shown that a traditional outbound marketing approach is $62 \%$ more expensive than inbound strategies (Halligan \& Shah, 2009). This increase in marketing efficiency has proven to be a double-edged sword. The barriers for entering into the marketing landscape have largely been removed; most companies have the resources to implement an effective marketing campaign. Therefore, there is more competition, more complexity, and more stimuli contending for the attention of the consumer.

In short, an attention economy has emerged in which the scarce resource competed for amongst companies is the attention of the consumer. Information is no longer in short supply but abundantly and overwhelmingly available at the consumer's disposal. The field of marketing has long since begun the evolution away from the generic and impersonal broadcasting of information; nevertheless, industry trends demonstrate record levels of television and signage advertising. This study represents yet another nail in the coffin of traditional outbound methods of reaching consumers. Though more money is spent on 
marketing through sport than through any other context, the presented research provides evidence that this setting represents a less effective and potentially overpriced advertising channel.

Considering the previously discussed substantial costs associated with event marketing, the dubious means for appraising its efficacy is alarming. Thus, it is presently argued that more primary research is necessary in order to quantify the psychological and behavioral effects of marketing stimuli. The current study provides a measurement of the cognitive returns generated through event marketing. For example, participants demonstrated an explicit recollection of $37 \%$ of the commercial advertising that they were exposed to during a sporting event, and $15 \%$ of this information was forgotten in the first 30 minutes. However, as discussed in the previous section, the major impetus for this research involves an exploration of the psychological processes relied upon by marketers in order to create and manipulate the brand representations maintained by consumers.

\section{Limitations and Future Research}

The majority of the limitations related to the present research involve unavoidable methodological restrictions. There are some limitations associated with survey research (e.g., social desirability bias, common method variance, extreme response bias, scale construction issues, etc.), represent one of the most significant challenges faced by emotions researchers, and they provided one of the many motivations for the implemented experimental design. An ideal approach to quantifying emotions may involve triangulating the measurement with a combination of self-report, observational, and diagnostic methods.

Next, free recall tasks (as was administered as an assessment of memory for commercial stimuli) are prone to a phenomenon known as retrieval induced forgetting (i.e., RIF; Anderson et al., 1994). The partial recall of a finite set of information has been shown to inhibit memory for the remainder of the set. Participants were given the task of recalling a set of 12 brands presented as commercial advertising. RIF refers to the interference that takes place as items within the set are recalled. These effects may lead to an underestimation of consumer memory for commercial advertising. However, due to the counterbalancing of items implemented into the design, this underestimation should be uniform across the stimuli. Therefore, RIF effects should not have an influence upon the overall conclusions of the study. Finally, an additional concern involves the lack of consistency regarding the sponsorship stimuli across the conditions. Unfortunately, restrictions were necessarily placed upon the selection of video stimuli for the study, and we were unable to find two suitable matches with the exact same sponsors. Therefore, three of the six sponsors differed across the studies. The findings indicated that memory did not vary across the two sets of sponsors.

\section{References}

Alpert, J. I., \& Alpert, M. I. (1990). Music influences on mood and purchase intentions. Psychology and Marketing, 7(2), 109-133. https://doi.org/10.1002/ mar.4220070204

Ashby, F. G., Valentin, V. V., \& Turken, A. U. (2002). The effects of positive affect and arousal and working memory and executive attention: Neurobiology and computational models. In S. C. Moore \& M. Oaksford (Eds.), Emotional cognition: From brain to behaviour (pp. 245-287). John Benjamins Publishing Company. https://doi.org/10. 1075/aicr.44.11ash

Anderson, M. C., Bjork, R. A., \& Bjork, E. L. (1994). Remembering can cause forgetting: Retrieval dynamics in long-term memory. Journal of Experimental Psychology, 20(5), 1063-1087. https://doi.org/10.1037/0278-7393.20.5.1063

Ashkanasy, N. M., \& Cooper, C. L. (Eds.). (2008). Research companion to emotion in organizations. 
Edward Elgar Publishing.

Babin, B. J., Boles, J. S., \& Darden, W. R. (1995). Salesperson stereotypes, consumer emotions, and their impact on information processing. Journal of the Academy of Marketing Science, 23(2), 94-105. https://doi.org/10.1177/0092070395232002

Baddeley, A. (2013). Working memory and emotion: Ruminations on a theory of depression. Review of General Psychology, 17(1), 20-27. https://doi.org/ 10.1037/a0030029

Bagozzi, R. P., Gopinath, M., \& Nyer, P. U. (1999). The role of emotions in marketing. Journal of the Academy of Marketing Science, 27(2), 184-206. https://doi.org/10.1177/0092070399272005

Bearden, W. O., Netemeyer, R. G., \& Haws, K. L. (Eds.). (2011). Handbook of Marketing Scales: Multi-item Measures for Marketing and Consumer Behavior Research (Third ed.). Sage Publications.

Bee, C. C., \& Havitz, M. E. (2010). Exploring the relationship between involvement, fan attraction, psychological commitment and behavioural loyalty in a sports spectator context. International Journal of Sports Marketing and Sponsorship, 11(2), 37-54. https://doi.org/10.1108/IJSMS-11-02-2010-B004

Bee, C. C., \& Madrigal, R. (2012). It's not whether you win or lose; It's how the game is played. Journal of Advertising, 41(1), 47-58. https://doi.org/10.2753 /JOA0091-3367410104

Bjork, R. A. (1989). Explaining dissociations between implicit and explicit measures of retention: A processing account. In H. L. Roediger \& F. I. M. Craik (Eds.), Varieties of Memory and Consciousness: Essays in Honour of Endel Tulving (pp. 309-330). Lawrence Erlbaum Associates.

Bower, G. H. (1981). Mood and memory. American Psychologist, 36(2), 129-148. https://doi.org/10.10 37/0003-066X.36.2.129

Bower, G. H., Gilligan, S. G., \& Monteiro, K. P. (1981). Selectivity of learning caused by affective states. Journal of Experimental Psychology: General, 110(4), 451-473. https://doi.org/10.1037/0096-3445.
110.4.451

Bower, G. H., Monteiro, K. P., \& Gilligan, S. G. (1978). Emotional mood as a context for learning and recall. Journal of Verbal Learning and Verbal Behavior, 17(5), 573-585. https://doi.org/10.1016/ S0022-5371(78)90348-1

Broach Jr, V. C., Page Jr, T. J., \& Wilson, R. D. (1995). Television programming and its influence on viewers' perceptions of commercials: The role of program arousal and pleasantness. Journal of Advertising, 24(4), 45-54. https://doi.org/10.1080/ 00913367.1995 .10673488

Brown, S. C., \& Craik, F. I. M. (2000). Encoding and retrieval of information The Oxford Handbook of Memory. Oxford University Press.

Cacioppo, J. T., Martzke, J. S., Petty, R. E., \& Tassinary, L. G. (1988). Specific forms of facial EMG response index emotions during an interview: From Darwin to the continuous flow hypothesis of affect-laden information processing. Journal of Personality and Social Psychology, 54(4), 592-604.

Chiappetta. (2009, July 6). A Look at 100 Memorable UFC Fights, Retrieved December 29, 2012, from http://sports.espn.go.com/extra/mma/news/story?id $=4037508$

Choi, N. H., Jung, J. M., Oyunbileg, T., \& Yang, P. (2016). The impact of emotional arousal levels and valence on product evaluations: From regulatory goal perspective. European Journal of Marketing, 50(1/2), 78-99. https://doi.org/10.1108/EJM-09-2013 $-0481$

Clark, M. S., \& Isen, A. M. (1982). Toward understanding the relationship between feeling states and social behavior. In A. H. Hastorf \& A. M.Isen (Eds.), Cognitive Social Psychology(pp. 71-108). Elsevier.

Cohen, J. (1977). Statistical Power Analysis for the Behavioral Sciences. Academic Press.

Cohen, J. (1992). A power primer. Psychological bulletin, 112(1), 155-159. https://doi.org/10.1037/ 0033-2909.112.1.155 
Coles, K., \& Tomporowski, P. D. (2008). Effects of acute exercise on executive processing, short-term and long-term memory. Journal of Sports Sciences, 26(3), 333-344. https://doi.org/10.1080/02640410 701591417

Conway, A. R. A., \& Engle, R. W. (1994). Working memory and retrieval: A resource-dependent inhibition model. Journal of Experimental Psychology: General, 123(4), 354-373. https://doi. org/10.1037/0096-3445.123.4.354

Cotton, J. L. (2006). A review of research on Schachter's theory of emotion and the misattribution of arousal. European Journal of Social Psychology, 11(4), 365-397. https://doi.org/10.1002/ejsp.2420110403

Davidson, R. J., Pizzagalli, D., Nitschke, J. B., \& Kalin, N. H. (2003). Parsing the subcomponents of emotion and disorders of emotion: Perspectives from affective neuroscience. In R. J. Davidson, K. R. Scherer \& H. H. Goldsmith (Eds.), Handbook of Affective Sciences (1st ed., pp. 8-24). Oxford University Press.

Davidson, R. J., Scherer, K. R., \& Goldsmith, H. H. (2003). Handbook of Affective Sciences (1st ed.). Oxford University Press.

Duffy, N. (2004). Passion branding: harnessing the power of emotion to build strong brands. John Wiley \& Sons.

Dukas, R. (2009). Evolutionary biology of limited attention. In L. Tommasi, M. A. Peterson \& L. Nadel (Eds.), Cognitive Biology: Evolutionary and Developmental Perspectives on Mind, Brain, and Behavior (pp. 147-161). MIT Press.

Eich, E. (1995). Searching for mood dependent memory. Psychological Science, 6(2), 67-75. https://doi.org/ 10.1111/j.1467-9280.1995.tb00309.x

Ekman, P., \& Friesen, W. V. (1978). Facial Action Coding System: A Technique for the Measurement of Facial Movement. Consulting Psychologists Press.

Eastwood, J. D., Smilek, D., \& Merikle, P. M. (2001). Differential attentional guidance by unattended faces expressing positive and negative emotion. Attention, Perception, \& Psychophysics, 63(6), 1004-1013. https://doi.org/10.3758/BF03194519

Faul, F., Erdfelder, E., Lang, A. G., \& Buchner, A. (2007). A flexible statistical power analysis program for the social, behavioral, and biomedical sciences. Behavior Research Methods, 39(2), 175-191. Retrieved from http://www.gpower.hhu.de/

Flynn, L. R., \& Goldsmith, R. E. (1999). A short, reliable measure of subjective knowledge. Journal of Business Research, 46(1), 57-66. https://doi.org/10. 1016/S0148-2963(98)00057-5

Funk, D. C., Mahony, D. F., \& Ridinger, L. L. (2002). Characterizing consumer motivation as individual difference factors: Augmenting the sports interest inventory (SII) to explain level of spectator support. Sport Marketing Quarterly, 11(1), 33-43. https://digitalcommons.odu.edu/hms_fac_pubs/34

Gantz, W., Wang, Z., Paul, B., \& Potter, R. F. (2006). Sports versus all comers: Comparing TV sports fans with fans of other programming genres. Journal of Broadcasting \& Electronic Media, 50(1), 95-118. https://doi.org/10.1207/s15506878jobem5001_6

Godden, D. R., \& Baddeley, A. D. (1975). Context-dependent memory in two natural environments: On land and underwater. British Journal of Psychology, 66(3), 325-331. https://doi. org/10.1111/j.2044-8295.1975.tb01468.x

Gottman, J. M., \& Krokoff, L. J. (1989). Marital interaction and satisfaction: A longitudinal view. Journal of Consulting and Clinical Psychology, 57(1), 47-52. https://doi.org/10.1037/0022-006X. 57.1.47

Goulding, C. (2002). An Exploratory Study of Age Related Vicarious Nostalgia and Aesthetic Consumption. In M. B. Susan \& N. Kent (Eds.), Advances in Consumer Research (Vol 29, pp. 542-546). Association for Consumer Research.

Halligan, B., \& Shah, D. (2009). Inbound Marketing: Get Found using Google, Social Media, and Blogs. Hoboken, NJ: John Wiley \& Sons. 
Hartman, M., \& Hasher, L. (1991). Aging and suppression: Memory for previously relevant information. Psychology and Aging, 6(4), 587-594. https://doi.org/10.1037/0882-7974.6.4.587

Hill, B., \& Green, B. C. (2012). Repeat participation as a function of program attractiveness, socializing opportunities, loyalty and the sportscape across three sport facility contexts. Sport Management Review, 15(4), 485-499. https://doi.org/10.1016/j.smr. 2012.03.006

Holak, S. L., \& Havlena, W. J. (1998). Feelings, fantasies, and memories: An examination of the emotional components of nostalgia. Journal of Business Research, 42(3), 217-226. https://doi.org/ 10.1016/S0148-2963(97)00119-7

Holbrook, M. B., \& Batra, R. (1987). Assessing the role of emotions as mediators of consumer responses to advertising. Journal of Consumer Research, 14(3), 404-420. https://doi.org/10.1086/209123

Hsieh, J. K., Hsieh, Y. C., Chiu, H. C., \& Yang, Y. R. (2014). Customer response to web site atmospherics: Task-relevant cues, situational involvement and PAD. Journal of Interactive Marketing, 28(3), 225-236. https://doi.org/10.1016/ j.intmar.2014.03.001

James, W. (1948). What is emotion? 1884. In W. Dennis (Ed.), Readings in the history of psychology (pp. 290-303). Appleton-Century-Crofts. https://doi.org/ 10.1037/11304-033.

Kang, J. H., Bagozzi, R. P., \& Oh, J. (2011). Emotions as antecedents of participant sport consumption decisions: A model integrating emotive, self-based, and utilitarian evaluations. Journal of Sport Management, 25(4), 314-325. https://doi.org/10.1123 /jsm.25.4.314

Kahneman, D. (1973). Attention and Effort. Prentice-Hall.

Kapucu, A., Kılıç, A., Özkılıç, Y., \& Sarıbaz, B. (2021). Turkish Emotional Word Norms for Arousal, Valence, and Discrete Emotion Categories. Psychological Reports, 124(1), 188-209. https://doi. org $/ 10.1177 / 0033294118814722$

Kensinger, E. A. (2004). Remembering emotional experiences: The contribution of valence and arousal. Reviews in the Neurosciences, 15(4), 241-252. https://doi.org/10.1515/REVNEURO.2004. 15.4.241

Kim, Y. K., \& Trail, G. (2011). A conceptual framework for understanding relationships between sport consumers and sport organizations: A relationship quality approach. Journal of Sport Management, 25(1), 57-69. https://doi.org/10.1123/jsm.25.1.57

Kirsh, D. (2000). A few thoughts on cognitive overload. Intellectica, 30(1), 19-51.

Kwak, D. H., Kim, Y. K., \& Hirt, E. R. (2011). Exploring the role of emotions on sport consumers' behavioral and cognitive responses to marketing stimuli. European Sport Management Quarterly, 11(3), 225-250. https://doi.org/10.1080/16184742.2011. 577792

Lim, C. H., Martin, T. G., \& Kwak, D. H. (2010). Examining television consumers of mixed martial arts: The relationship among risk taking, emotion, attitude, and actual sport-mediaconsumption behavior. International Journal of Sport Communication, 3(1), 49-63. https://doi.org/10.11 23/ijsc.3.1.49

Lövheim, H. (2011). A new three-dimensional model for emotions and monoamine neurotransmitters. Medical Hypotheses, 78(2), 341-348. https://doi.org/ 10.1016/j.mehy.2011.11.016

Matson J.L., Montrenes J. (2020) Assessing Autism in Dual Diagnosis. In J. Matson (Ed.), Handbook of Dual Diagnosis. Autism and Child Psychopathology Series. (pp. 251-266) Springer Cham. https://doi.org/10.1007/978-3-030-46835-4 16

Mattes, J., \& Cantor, J. (1982). Enhancing responses to television advertisements via the transfer of residual arousal from prior programming. Journal of Broadcasting \& Electronic Media, 26(2), 553-566. https://doi.org/10.1080/08838158209364024 
Mayeda, D. T., \& Ching, D. E. (2008). Fighting for Acceptance: Mixed Martial Artists and Violence in American Society. Universe.

McNally, R. J. (1999). Panic and phobias. In T. Dalgleish \& M. J. Power (Eds.), Handbook of Cognition and Emotion (pp. 479-496), John Wiley \& Sons, Inc.

Mehrabian, A. (1996). Analysis of the big-five personality factors in terms of the PAD temperament model. Australian Journal of Psychology, 48(2), 86-92. https://doi.org/10.1080/ 00049539608259510

Mehrabian, A., \& Russell, J. A. (1974). An Approach to Environmental Psychology. MIT Press.

Mitchell, K. J., Livosky, M., \& Mather, M. (2011). The weapon focus effect revisited: The role of novelty. Legal and Criminological Psychology, 3(2), 287-303. https://doi.org/10.1111/j.2044-8333.1998. tb00367.x

Morris, C. D., Bransford, J. D., \& Franks, J. J. (1977). Levels of processing versus transfer appropriate processing. Journal of Verbal Learning and Verbal Behavior, 16(5), 519-533. https://doi.org/10.1016/ S0022-5371(77)80016-9

Murdock Jr, B. B. (1962). The serial position effect of free recall. Journal of Experimental Psychology, 64(5), 482-488. https://doi.org/10.1037/h0045106

Myers, J., \& Sar, S. (2015). The influence of consumer mood state as a contextual factor on imagery-inducing advertisements and brand attitude. Journal of Marketing Communications, 21(4), 284-299. https://doi.org/10.1080/13527266. 2012.762421

Nairne, J. S. (1988). A framework for interpreting recency effects in immediate serial recall. Memory \& Cognition, 16(4), 343-352. https://doi.org/10.3758/ BF03197045

Nowlis, V. (1965). Factor Analytic Studies of the Mood Adjective Checklist. Rochester University, New York Department of Psychology.

Postman, L., \& Phillips, L. W. (1965). Short-term temporal changes in free recall. Quarterly Journal of Experimental Psychology, 17(2), 132-138. https://doi.org/10.1080/17470216508416422

Rainey, D. W., Yost, J. H., \& Larsen, J. (2011). Disappointment theory and disappointment among football fans. Journal of Sport Behavior, 34(2), 175-187.

Russell, J. A., Weiss, A., \& Mendelsohn, G. A. (1989). Affect Grid: A single-item scale of pleasure and arousal. Journal of Personality and Social Psychology, 57(3), 493-502.

Stapel, D. A. (2008). The secret life of emotions. Psychological Science, 19(4), 385-391. https://doi: 10.1111/j.1467-9280.2008.02097.x

Schiffenbauer, A. (1974). Effect of observer's emotional state on judgments of the emotional state of others. Journal of Personality and Social Psychology, 30(1), 31-35. https://doi.org/10.1037/h0036643

Scott, R. K., \& Goff, D. H. (1988). How excitation from prior programming affects television news recall. Journalism \& Mass Communication Quarterly, 65(3), 615-620. https://doi.org/10.1177/107769908 806500308

Sherman, E., Mathur, A., \& Smith, R. B. (1997). Store environment and consumer purchase behavior: mediating role of consumer emotions. Psychology \& Marketing, 14(4), 361-378. https://doi.org/10.10 02/(SICI)1520-6793(199707)14:4<361::AID-MA $\mathrm{R} 4>3.0 . \mathrm{CO} ; 2-7$

Steptoe, A., Pollard, T. M., \& Wardle, J. (1995). Development of a measure of the motives underlying the selection of food: the food choice questionnaire. Appetite, 25(3), 267-284.

Trail, G., \& James, J. (2001). The Motivation Scale for Sport Consumption: Assessment of the Scale's Psychometric Properties. Journal of Sport Behavior, 24(1), 108-127.

Trampe, D., Stapel, D. A., Siero, F. W., \& Mulder, H. (2010). Beauty as a tool: The effect of model attractiveness, product relevance, and elaboration likelihood on advertising effectiveness. Psychology \& Marketing, 27(12), 1101-1121. 
Tulving, E., \& Thomson, D. M. (1973). Encoding specificity and retrieval processes in episodic memory. Psychological review, 80(5), 352-373. https://doi.org/10.1037/h0020071

Vuilleumier, P., \& Schwartz, S. (2001). Emotional facial expressions capture attention. Neurology, 56(2), 153-158. https://doi.org/10.1212/WNL.56.2.153

Wann, D. L., Melnick, M. J., Russell, G. W., \& Pease, D. G. (2001). Sport fans: The psychology and social impact of spectators. Routledge.

Watson, D., Clark, L. A., \& Tellegen, A. (1988). Development and validation of brief measures of positive and negative affect: The PANAS scales. Journal of Personality and Social Psychology, 54(6), 1063-1070.

Weingartner, H., Miller, H., \& Murphy, D. L. (1977). Mood-state-dependent retrieval of verbal associations. Journal of Abnormal Psychology, 86(3), 276-284. https://doi.org/10.1037/0021-843X.
86.3.276

Wulfert, E., Roland, B. D., Hartley, J., Wang, N., \& Franco, C. (2005). Heart rate arousal and excitement in gambling: Winners versus losers. Psychology of Addictive Behaviors, 19(3), 311-316. https://doi.org/10.1037/0893-164X.19.3.311

Zajonc, R. B. (1980). Feeling and thinking: Preferences need no inferences. American Psychologist, 35(2), 151-175. https://doi.org/10.1037/0003-066X.35.2. 151

Zambardino, A., \& Goodfellow, J. (2007). Being 'Affective' in Branding? Journal of Marketing Management, 23(1-2), 27-37. https://doi.org/10.13 62/026725707X178530

Zuckerman, M., \& Lubin, B. (1965). Normative Data for the Multiple Affect Adjective Check List. Psychological Reports, 16(2), 438-438. https://doi. org/10.2466/pr0.1965.16.2.438 


\section{APPENDIX A \\ THE MODIFIED PAD SCALE}

Using the following scales, we would like for you to rate how you felt while you were watching the video. For example, on the first pair of adjectives if you felt unhappy, circle "1." If you felt happy, circle "7." If you felt somewhere in between, circle the number that best expresses how you felt.

While watching the video of the match, I felt...

\begin{tabular}{ccccccccc}
\hline \hline Unhappy & 1 & 2 & 3 & 4 & 5 & 6 & 7 & Happy \\
Annoyed & 1 & 2 & 3 & 4 & 5 & 6 & 7 & Pleased \\
Unsatisfied & 1 & 2 & 3 & 4 & 5 & 6 & 7 & Satisfied \\
Content & 1 & 2 & 3 & 4 & 5 & 6 & 7 & Gloomy \\
Despaining & 1 & 2 & 3 & 4 & 5 & 6 & 7 & Hopeful \\
Bored & 1 & 2 & 3 & 4 & 5 & 6 & 7 & Entertained \\
Stimulated & 1 & 2 & 3 & 4 & 5 & 6 & 7 & Relaxed \\
Excited & 1 & 2 & 3 & 4 & 5 & 6 & 7 & Calm \\
Sluggish & 1 & 2 & 3 & 4 & 5 & 6 & 7 & Frenzied \\
Jittery & 1 & 2 & 3 & 4 & 5 & 6 & 7 & Dull \\
Sleepy & 1 & 2 & 3 & 4 & 5 & 6 & 7 & Wide-awake \\
Unaroused & 1 & 2 & 3 & 4 & 5 & 6 & 7 & Aroused \\
\hline \hline
\end{tabular}

